\title{
Dielectric spectroscopy of aluminum oxide $\left(\gamma-\mathrm{Al}_{2} \mathrm{O}_{3}\right)$
}

\author{
M. M. Abdullah \\ Dept. of Physics, Promising Centre for Sensors and Electronic Devices (PCSED), \\ Faculty of Science and Arts, Najran University, Najran, \\ P. O Box-1988, Najran-11001, Saudi Arabia. \\ Corresponding author: abdullahphyzia@gmail.com
}

\begin{abstract}
Aluminum oxide $\left(\mathrm{Al}_{2} \mathrm{O}_{3}\right)$ are continuously demonstrating the functional characteristics in devices. The physiochemical properties of hydrothermally as-grown Aluminum oxide $\left(\mathrm{Al}_{2} \mathrm{O}_{3}\right)$ have been investigated in this research article. The as-prepared material was confirmed as $\gamma$-phase formation of $\mathrm{Al}_{2} \mathrm{O}_{3}$. The average crystallite size was found $\sim 78 \mathrm{~nm}$, whereas the particles were found in nano scale too. Moreover, the absence of impurity in EDS analysis, and the presence of the bending vibrations of Al-O-Al and Al-O band in FTIR characterization further confirmed the absence of impurity in the material. Evaluated dielectric properties such as a relatively high dielectric constant, and low dielectric loss indicated the good optical quality of $\gamma-\mathrm{Al}_{2} \mathrm{O}_{3}$. Impedance and modulus spectroscopic studies showed the non-Debye type relaxation in $\gamma-\mathrm{Al}_{2} \mathrm{O}_{3}$ with an average relaxation time of $5.8 \mu \mathrm{s}$. Overall, the dielectric spectroscopy analysis of $\gamma-\mathrm{Al}_{2} \mathrm{O}_{3}$ indicates the promising applications of $\gamma-\mathrm{Al}_{2} \mathrm{O}_{3}$ in devices as dielectrics.
\end{abstract}

Keywords: Dielectric properties; impedance spectroscopy; metal oxide; modulus spectroscopy; physical properties.

\section{Introduction}

Metal oxide semiconductor materials have often shown that they can serve as promising alternatives for use in electronic and optical devices [Armstrong et al., 1996; Othman et al., 2019; Abdullah et al.,2018; Preeti Singh et al., 2019]. Metal oxides are proving to be useful materials in a variety of applications, including dielectrics [Abdullah, 2017; Abdullah et al., 2014], sensors [Khaleel et al., 2020; Abdullah et al., 2015], photocatalysts [Faisal et al., 2012; Faisal et al., 2011], lithium-ion batteries [Wang et al., 2009; Guo et al., 2009], supercapacitors [Stoller et al., 2008], solar cells [Wang et al., 2008], and hydrogen storage devices [Ma et al., 2009]. In addition, the related electronic and optical nano-devices could be made more effective by using materials with low dimensional structures [Aqeel et al., 2018; Vilar et al., 2010]. This is due to enormous emergence in the ratio of active surface to volume as a result of the decrease in particle sizes. There are many methods to synthesize the low particle size materials [Abdullah, 2020; Kandasamy et al., 2015]. Among them, hydrothermal method was found suitable to prepare the low dimensional metal oxides. The main advantage of this method over the other method of preparation is its low 
working temperature, easy process, low cost, and environmentally friendly route of preparation [Abdullah, 2020], whereas proper handling is needed during reaction hour because the reaction occurs at high pressure. Among various metal oxides, low dimensional aluminum oxide $\left(\mathrm{Al}_{2} \mathrm{O}_{3}\right)$ in pure form is very rarely studied [Hu et al., 2018; Kerasidou et al., 2014, Samaporna et al., 2019]. $\mathrm{Al}_{2} \mathrm{O}_{3}$ in bulk size, as a thin film, and mixed with some other element/compound is widely reported [Hasan et al., 2020; Nurhanna Badar et al., 2019; Aguilar-Frutis et al., 2001, Bishnupriya Behera 2020; Huiyun et al., 2020; Stolyarova et al., 2020]. Therefore, we have selected the alumina $\left(\mathrm{Al}_{2} \mathrm{O}_{3}\right)$ for the present study and opted the hydrothermal method for its low dimensional synthesis. The unit cell of $\mathrm{Al}_{2} \mathrm{O}_{3}$ belongs to the rhombohedral system of crystal structures. The lattice parameter of the unit cell was found as $\mathrm{a}=4.758 \AA, \mathrm{c}=12.996 \AA$ [Shankar Amalraj et al., 2019]. In general, there are various polymorphs of alumina like $\gamma-, \theta-, \kappa-, \alpha-$. Out of these $\alpha$ - phase was found stable, whereas remaining phases were found to exist in metastable phases. The unstable phases are the factor of the melting state of alumina and there corresponding cooling behavior [Jianyi et al., 2017]. Alumina is widely used as ceramic material [Hu Wei et al., 2018], as an adsorbent to remove arsenic from groundwater [Nurhanna Badar et al., 2019], for solar panel application [Shankar Amalraj et al., 2019], for stereolithography-based 3D-printing technology [Xiaohong Xu et al., 2020] in memory device [Imen M'rad et al., 2018], in pulsed arc erosion [Lee Li et al., 2020], as a dielectric material in the form of nanocomposites [Huiyun Ban et al., 2020; Stolyarova et al., 2020; Nguyen Anh Tuan et al., 2016]. Absolute dielectric spectroscopic properties such as dielectric permittivity, tangent loss, ac conductivity, impedance-modulus behavior of alumina is still needed to be recorded. We have therefore prepared a low dimensional $\mathrm{Al}_{2} \mathrm{O}_{3}$ material to explore the complete dielectric properties using frequency-dependent dielectric spectroscopy.

The dielectric behavior of materials such as dielectric permittivity, tangent loss, and ac conductivity are the effective bases for improving the efficiency level of the capacitor. Capacitor is the device that stores electrical energy in terms of charges. The higher the occurrence of charge polarization, enhances the capacitance of the capacitor. Dielectric is the means of charge polarization anomalies in a capacitor. The dielectric analysis depicts the dielectric matrix's dynamics as a result of the applied electrical field. Materials with high permittivity are advantageous to capacitor [Wang et al., 2018], memory device [Kingon et al., 2000], and high Kgate dielectric [Abdullah et al., 2011]. Smaller energy loss $(\tan \delta)$ in dielectric advocates the attired optical nature of the material. Cole-Cole plot illustrates the mechanism of relaxation taking place inside the matrix of dielectrics. Moreover, if the center of the semicircular Cole-Cole plot is on the real part of the impedance axis, then it shows the Deby form of relaxation in dielectrics. [Abdullah, 2020]. Nyquist plot reveals the effects of grain and grain boundary [Woo-Sik Jung, 2010].

\section{Experiment}

Aluminum oxide $\left(\mathrm{Al}_{2} \mathrm{O}_{3}\right)$ nanostructured material were successfully synthesized by hydrothermal technique. A solution of $\mathrm{pH} 10.5$ was prepared by mixing the $0.1 \mathrm{M} \mathrm{AlCl}_{2}$ in $100 \mathrm{ml}$ distilled water. The prepared solution was poured into a $100 \mathrm{ml}$ autoclave. The autoclave-containing solution was 
then placed inside a hydrothermal bomb to carry out the reactions under high pressure. The hydrothermal bomb in the autoclave was heated for 15 hours at $160{ }^{\circ} \mathrm{c}$. After cooling, the as prepared material was washed, dried, and annealed at $400{ }^{\circ} \mathrm{c}$ to remove the all-possible contaminations. The structural properties of the finally, obtained material was investigated by PXRD, FESEM, EDS, FTIR spectrometer, and Raman spectrometer. A UV-VIS-NIR spectrophotometer was used to assess the optical properties. Dielectric/impedance/modulus behavior was exploited as a function of frequency by an LCR Meter (supplied by MCP and Agilent) at room temperature.

\section{Results and discussion}

\subsection{Structural, morphological, elemental, and optical analysis}

The presence of sharp diffraction peaks in the observed XRD pattern (Fig. 1(a)) clearly shows the crystalline phase formation of the product. The clear broadening of the peaks further indicates the non-uniformity and big crystallite formation of the product. The recorded peaks in the XRD spectrum fit well with JCPDS data number 10-0425 and are consistent with the observed [Nurhanna Badar et al., 2019; Woo-Sik Jung, 2010] XRD spectrum. It confirms the $\gamma-\mathrm{Al}_{2} \mathrm{O}_{3}$ phase formation of the product. In general, the aluminum oxide may crystallize into $\mathrm{AlO}, \mathrm{AlO}_{2}$ or $\mathrm{Al}_{2} \mathrm{O}_{3}$ in various polymorphs of $\alpha-, \delta$-, $\gamma$-, etc, depending upon the calcination temperature and time of calcination. The $\gamma-\mathrm{Al}_{2} \mathrm{O}_{3}$ phase formation in this study showed that the hydrothermal method is appropriate for the synthesis of $\gamma-\mathrm{Al}_{2} \mathrm{O}_{3}$. The JCPDS data number 10-0425 was used to index the (hkl) values corresponding to each x-ray diffraction peak (Fig. 1(a)). Thus, the diffraction pattern demonstrates the growth of crystallites along (220), (311), (222), (400), (511), and (440) planes. Out of these planes, the fast growth is along (440) plane. This is due to the reactants' rapid adsorption along these planes. Moreover, the average crystallite size calculated using DebbyScherer formula [Farah Kanwal et al., 2021] for the titled compound $\gamma-\mathrm{Al}_{2} \mathrm{O}_{3}$ is $\sim 78 \mathrm{~nm}$. 

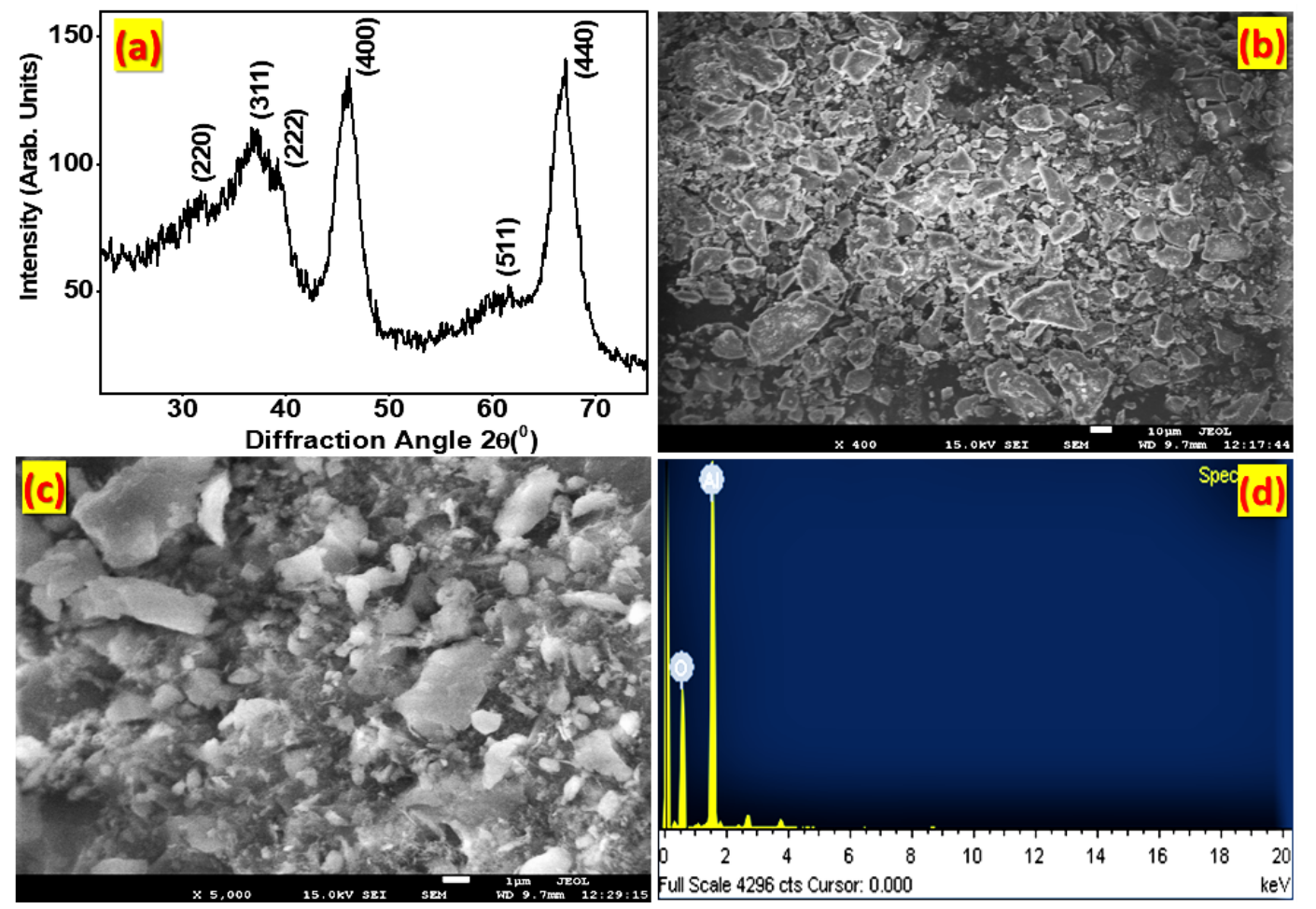

Fig. 1. shows (a) the powder XRD (b) Low magnification FESEM image, (c) high magnification FESEM image, and (d) EDS spectrum of the as-grown $\gamma-\mathrm{Al}_{2} \mathrm{O}_{3}$.

Figure 1(b), and 1(c) displays the recorded morphology of the as-calcined $\gamma-\mathrm{Al}_{2} \mathrm{O}_{3}$ polycrystalline material at a relatively low and high magnification, respectively using FESEM. Figure 1(b) shows the dense growth of uniformly distributed particles which resembles mosaic like features. The figure 1(c) clearly demonstrates the rock like shapes of various sizes. The dimensional feature of the as-grown material shows the particle sizes in nano and micro range. Most of them are in nanorange. A minuscule inspection of Figure 1(c) shows a few foams like morphology also. Furthermore, the presence of only Aluminum (Al) and Oxygen (O) in the EDS study (figure 1(d)), as well as the absence of any other ingredient, confirms the pureness of the as-calcined product.

The pureness of $\gamma-\mathrm{Al}_{2} \mathrm{O}_{3}$ was further inspected in FTIR analysis using the obtained characteristic peaks represented in the spectrum (Figure 2(a)). In general, the characteristic peak below the wave number $1000 \mathrm{~cm}^{-1}$ attributes the metal-oxygen bonding for metal-oxides [Abdullah, 2020, Somaparna Ghosh et al., 2019]. The band observed at $\sim 600$, and $770 \mathrm{~cm}^{-1}$ indicate the presence of the bending vibrations of Al-O-Al, and Al-O band, respectively. Whereas, the two other bands at 1625 and $3453 \mathrm{~cm}^{-1}$ shows the $-\mathrm{OH}$ stretching vibrations (Abdullah et al., 2020; Saif A. Naayi et al., 2018; Sathiya Narayanan et al., 2019). These band are due to the physiosorbed water molecule, that was captured by the material during pellet preparation. Thus, the presence of meta-Oxide (Al-O) characteristic peak ascertains the product purity. 

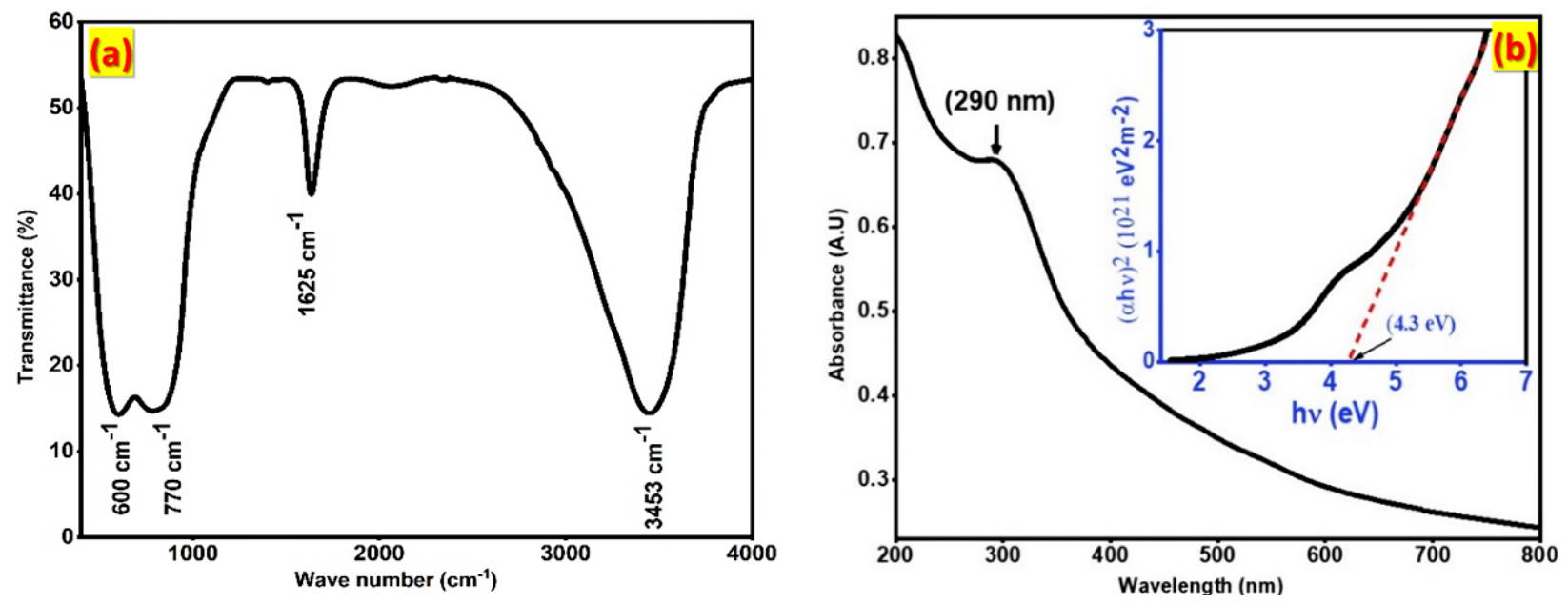

Fig. 2. (a) shows the FTIR spectra of $\gamma-\mathrm{Al}_{2} \mathrm{O}_{3}$. (b) shows the UV-VIS absorption spectra and energy band gap plot (inset), for $\gamma-\mathrm{Al}_{2} \mathrm{O}_{3}$.

Figure 2(b) displays the absorption spectra of $\gamma-\mathrm{Al}_{2} \mathrm{O}_{3}$ materials. The spectrograph demonstrates the universal pattern of absorption over frequency. The shoulder in the absorption graph $\sim 290 \mathrm{~nm}$ indicates the cut-off wavelength. The presence of cut-off wavelength indicates the semiconducting behavior of the material and therefore, an energy bandgap can be evaluated using tauc's relation [Abdullah et al, 2013]. A graph was plotted between "hv" and " $\alpha \mathrm{h} v$ " according to tauc's relationship, as shown in inset-figure (2). This figure shows that the direct band gap of the asgrown material is $4.3 \mathrm{eV}$. The occurrence of high band gap is mainly because of the low dimension of the material's particles. As the dimension decreases, the quantum confinement effect becomes more pronounced.

\subsection{Dielectric analysis}

The variation in $\varepsilon^{\prime}$ with frequency is represented in figure 3(a). The value of $\varepsilon^{\prime}$ decreases with frequency. A relatively higher values of $\varepsilon^{\prime}$ contributes the higher values of capacitance. Thus, the high value of $\varepsilon^{\prime}$ enhances the energy storage ability of the capacitor. The presence of all four types of polarization is demonstrated by a significantly high $\varepsilon^{\prime}$ in the initial frequency domain [Abdullah et al., 2011]. However, the value of $\varepsilon^{\prime}$ decreases rapidly in this frequency domain. This occurs due to a decrease in the space charge polarization effect [Abdullah, 2020]. Thus, space charge polarization is the pre dominant factor in $\gamma-\mathrm{Al}_{2} \mathrm{O}_{3}$ dielectrics in the presence of applied ac signal. The low frequency ac signal generates higher stretching effect inside the matrix due to random mobility of free charges. As frequency increases, impact of stretching effect inside the matrix decreases. Thus, the higher $\varepsilon^{\prime}$ in lower frequency cites are basically the impact of stronger stretching effects, arises due to the space charge polarization. 


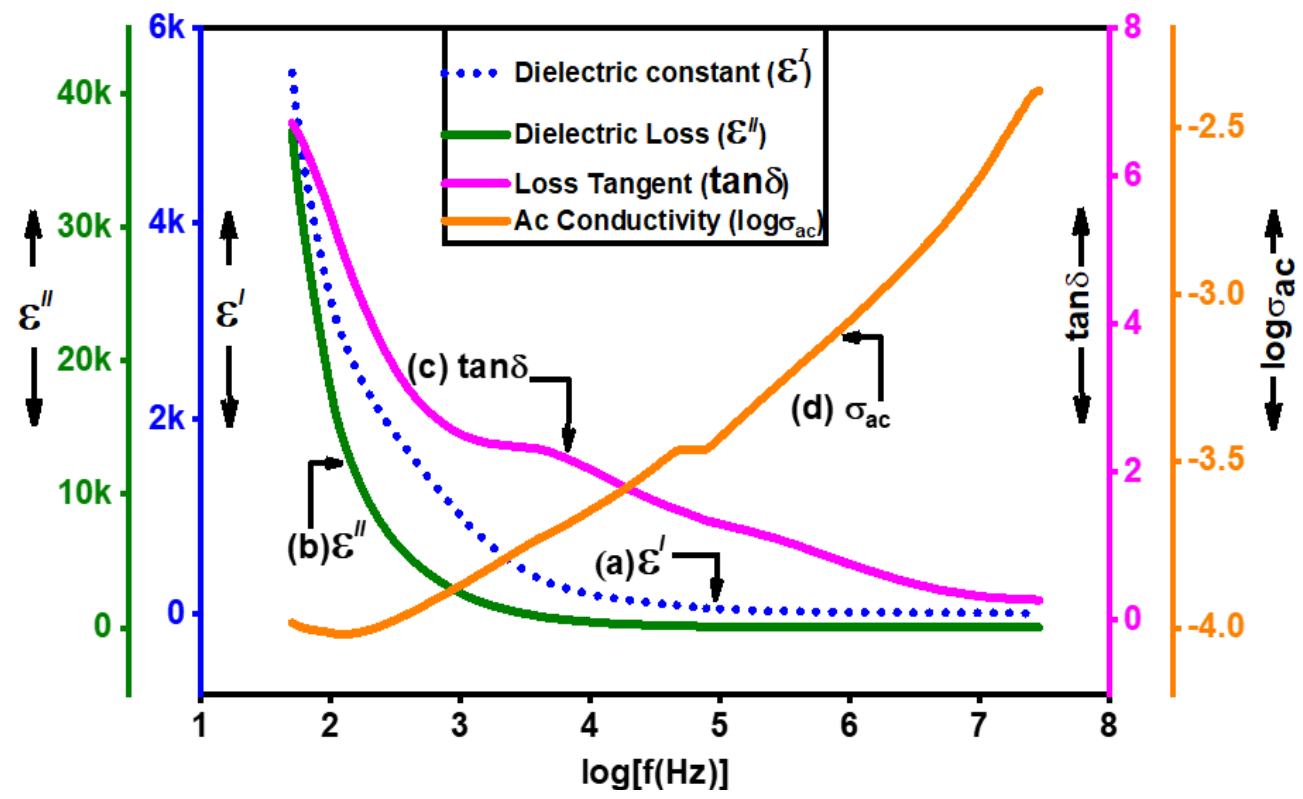

Fig. 3. shows the variation in (a) dielectric constant (b) dielectric loss, (c) loss tangent, and (d) ac conductivity in the frequency domain from $100 \mathrm{~Hz}$ to $30 \mathrm{MHz}$.

The response graph (Figure 3(b)) of dielectric loss $\left(\varepsilon^{\prime \prime}\right)$ reflects the pattern similar to $\varepsilon^{\prime}$ (Figure 3(a)). The mechanism remains same, and thus, it has been determined that the space charge polarization is to account for the strong impact of $\varepsilon^{\prime \prime}$ within the low frequency cites. Furthermore, the absent of a peak in the plotted graph (Figure 3(b)) shows that the dielectric relaxations in $\gamma$ $\mathrm{Al}_{2} \mathrm{O}_{3}$ is not of the Deby form [Abdullah, 2020; Somaparna Ghosh et al., 2019]. Dielectric loss tangent $\left(\tan \delta\right.$ ) graph (Figure 3(c)) also illustrates the almost similar pattern of $\varepsilon^{\prime}$ and $\varepsilon^{\prime \prime}$. That is the value of $\tan \delta$ decreases with increasing frequency. From the graph it has been found that the tangent loss is substantially low (below 7). Low tan $\delta$ indicates the good crystallinity, less density defects, and good optical behavior of the material, and therefore, could be potentially used in nonlinear optical materials [Abdullah et al., 2011].

The graph of ac conductivity $\left(\sigma_{\mathrm{ac}}\right)$ is shown in figure $3(\mathrm{~d})$. The value of $\sigma_{\mathrm{ac}}$ was evaluated using the formula $\sigma_{\mathrm{ac}}=2 \pi f \varepsilon_{\mathrm{o}} \varepsilon^{\prime} \tan \delta$, where the symbols have their usual meanings [Abdullah, 2020, Preeti et al., 2013]. The plotted graph shows almost the uniform value of $\sigma_{\text {ac }}$ within initial frequency cite. Nearly a uniform $\sigma_{\mathrm{ac}}$ within this non-uniform frequency cite indicates the continuation of dc conductivity. Moreover, $\sigma_{\mathrm{ac}}$ was found increasing with frequency in accordance to the frequency power law $\left(\sigma_{\mathrm{ac}} \propto \omega^{\mathrm{n}}\right)$ in the remaining higher frequencies region. In principle, the dc continuation in low frequency zone is due to successful hop of charges, while ac continuation in remaining higher frequencies is a consequence of unsuccessful hoping of charges as per jump relaxation model [Abdullah 2020].

\subsection{Evaluation of impedance spectroscopy}

Impedance is a kind of obstruction induced by the circuit against the flow of alternating current. The impedance spectroscopic behavior of the circuit may be investigated by studying the real $\left(Z^{\prime}\right)$ 
and imaginary $\left(Z^{\prime \prime}\right)$ components of complex impedance $\left(Z^{*}=Z^{\prime}+i Z^{\prime \prime}\right)$. Figure $4(\mathrm{a}-\mathrm{i})$ represents the variance in $Z^{\prime}$ in the experimented frequency region. Overall, $Z^{\prime}$ declines as frequency increases. The fast decrease in $Z^{\prime}$ in low frequency domain is mainly a result of the polarization of space charge, and thus suggests dominant capacitive activity in the circuit. Whereas, the shallow decrease of $Z^{\prime}$ in higher frequency domain suggests dominant resistive activity in the circuit. It's because of weak polarization of space charge.

A nearly similar trend was observed for $Z^{\prime \prime}$ (fig. 4(a-ii)) in $\gamma-\mathrm{Al}_{2} \mathrm{O}_{3}$. Overall, the decreasing value in real/complex impedance is mainly the consequences of space charge polarization. The appearance of a peak shows the occurrence of single relaxation process of non-Deby type [Abdullah, 2020; Somaparna Ghosh et al., 2019). The FWHM of the peak was found to be equal to $\sim 1.5$ decades which is higher over 1.14 decades. This further confirms the relaxation of nonDebye type in $\gamma-\mathrm{Al}_{2} \mathrm{O}_{3}$. This relaxation time was evaluated by using the relation $2 \pi \mathrm{f}_{\max } \tau=1$ and was found to be equal to $5.8 \mu \mathrm{s}$. Here, $\mathrm{f}_{\max }$ is the frequency at which the amplitude of the peak is highest. For present investigation, $\mathrm{f}_{\max }=27500$. Moreover, type of relaxation in $\mathrm{Al}_{2} \mathrm{O}_{3}$ may well explored by plotting the graph between $Z^{\prime}$ and $Z^{\prime \prime}$ i.e., the Nyquist plot (Figure 4 (a-iii) Inset). The presence of a single arc in Nyquist plot with center of the arc not lying on $Z^{\prime}$ validates the influence of interfacial polarization as well as non-Debye type relaxation.
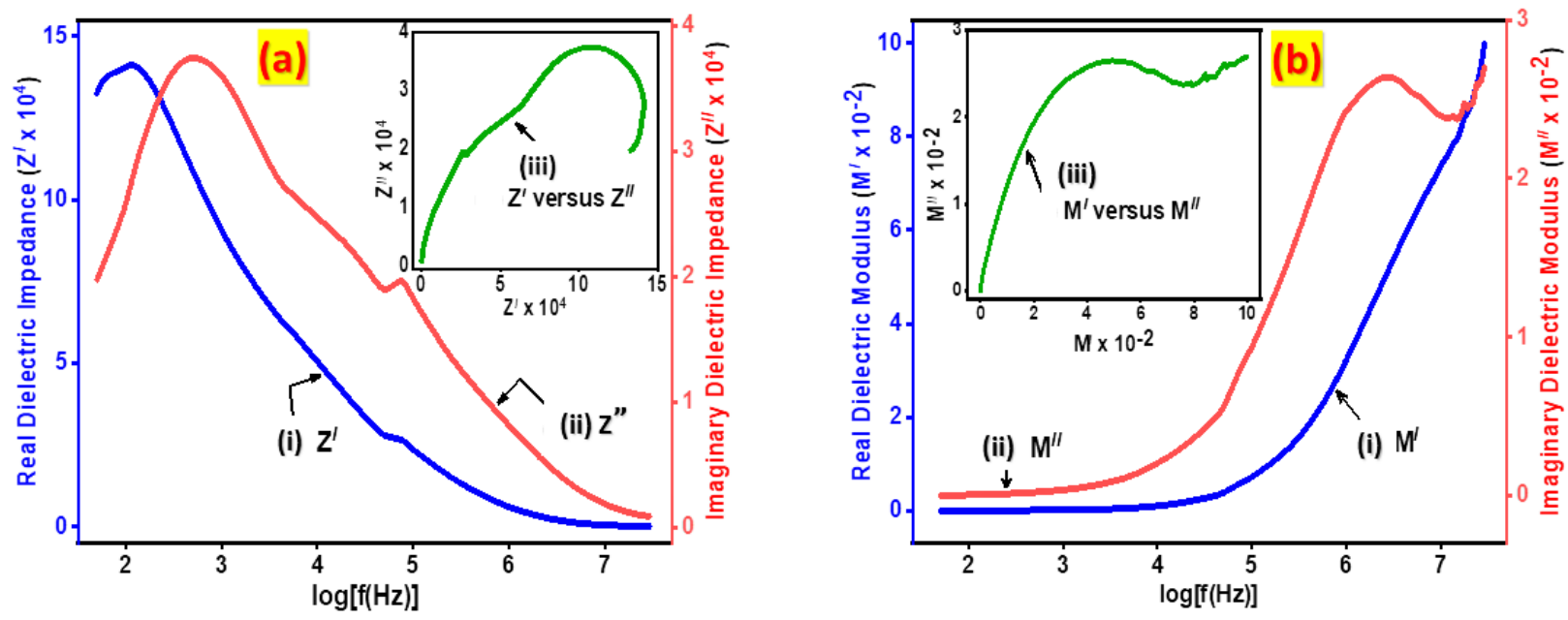

Fig. 4. (a) shows graph of (i) $Z^{\prime}$ (ii) $Z^{\prime \prime}$, and (iii) Nyquist plot (b) shows graph of (i) $M^{\prime}$ (ii) $M^{\prime \prime}$, and (iii) Cole-Cole plot of $\gamma-\mathrm{Al}_{2} \mathrm{O}_{3}$.

\subsection{Evaluation of modulus spectroscopy}

The dielectric phenomena in $\mathrm{Al}_{2} \mathrm{O}_{3}$ may also be investigated by studying the modulus spectroscopy. Figure 4(b-i) and 4(b-ii), represents the characteristic graphs of real $\left(M^{\prime}\right)$ and imaginary $\left(M^{\prime \prime}\right)$ electric modulus. Within initial frequency cites, values related to $M^{\prime}$ and $M^{\prime \prime}$ are very low and is close to zero. This shows the absence of electrode polarization. While, in the remaining high frequency domain, $\left(M^{\prime}\right)$ and $\left(M^{\prime \prime}\right)$ was found increasing with frequency. This 
indicates the presence of polarization effect and thus the occurrence of relaxation processes. Low values of $M^{\prime}$ and $\mathrm{M}^{\prime \prime}$ within lower frequency cites indicates the phenomenon of long-range mobility of charges. The appearance of shoulder in $\left(M^{\prime \prime}\right)$ further confirms the relaxation processes in the dielectric. [Bhagwanti S. Bishnoi et al., 2014]. In addition, the mode of relaxation could also be investigated using Cole-Cole plot. The plotted graph of Cole-Cole (inset-fig. 4(b-iii)) demonstrates the arc of a circle. The arc's core does not appear to be on the $M^{\prime}$ axis. This supports the idea of calming processes that aren't Debye-like. Since the center of the as plotted arc should lie on the $\mathrm{M}^{\prime}$-axis for a Deby like relaxation.

\section{Conclusion}

The hydrothermal route of preparation was found to be effective in synthesizing $\gamma-\mathrm{Al}_{2} \mathrm{O}_{3}$ nanostructures. As-prepared material was detected as of crystalline structure. The purity of the product was further verified by elemental analysis. This substance was discovered to have a strong optical consistency. The effect of space charge polarization in dielectric phenomena was found dominant. The material demonstrated non-Deby kind of relaxation with a relaxation time of 5.8 micro-seconds. The possible application of $\gamma-\mathrm{Al}_{2} \mathrm{O}_{3}$ in the construction of effective dielectric devices was discovered by this dielectric research.

\section{ACKNOWLEDGEMENTS}

Authors would like to thank the Deanship of Scientific Research, Najran University, P.O. Box 1988, Najran, 11001, Kingdom of Saudi Arabia, for the financial support of this work under the project Grant Number: NU/ESCI/17/085.

\section{References}

Abdullah M. M. (2017). Structural Characterizations and Frequency Dependent Dielectric Properties of As-Prepared $\mathrm{Gd}_{2} \mathrm{O}_{3}$ Nanorods. Current Nanoscience, 13: 1-5

Abdullah M. M. (2020). Facile Growth, Physical Characterization, and Dielectric Response of As-Grown NiO Nanostructures. Journal of king saud university - science, 32: 1048-1054

Abdullah M. M. (2021). Consequences of frequency and temperature on the ac-conductivity in $\varepsilon$-GaSe semiconductor single crystal. Results in Physics, 25: 104220.

Abdullah M. M., Ajmal Khan M., Bhagavannarayana G., Wahab M. A. (2011). Structural and Dielectric Studies of Pure and Mn Doped GaSe. Science of Advanced materials, 3: 1- 6.

Abdullah M. M., Mohammad M. Rahman, Houcine Bouzid, M. Faisal, Sher Bahadur Khan, Al-Sayari S. A., Adel A. Ismail. (2015). Sensitive and fast response ethanol chemical sensor based on as-grown $\mathrm{Gd}_{2} \mathrm{O}_{3}$ nanostructures. J. Rare Earths, 33: 214-220. 
Abdullah M. M., Mohammad Shabib Akhtar, Saleh M. Abbas. (2018). Facile Growth and Promising Applications of Cobalt Oxide $\left(\mathrm{Co}_{3} \mathrm{O}_{4}\right)$ Nanoparticles as Chemi-Sensor and Dielectric Material. Current Nanoscience, 14: 1-9

Abdullah M. M., Siddiqui S. A., Saleh M. Al-Abbas. (2020). Physio-chemical Properties and Dielectric Behaviour of As-Grown Managanese Oxide $\left(\gamma-\mathrm{Mn}_{2} \mathrm{O}_{3}\right)$ Nanoparticles. J. Electro. Mater., 49(7): 4410-4417.

Abdullah M.M., Preeti Singh, Mohd Hasmuddin, Bhagavannarayana G., Wahab M. A. (2013). In situ growth and ab initio optical characterizations of amorphous $\mathrm{Ga}_{3} \mathrm{Se}_{4}$ thin film: A new chalcogenide compound semiconductor thin film. Scripta Materialia, 69: 381-384.

Abdullah, M. M., Fahd M. Rajab, Saleh M. Al-Abbas, (2014). Structural and optical characterization of $\mathrm{Cr}_{2} \mathrm{O}_{3}$ nanostructures: Evaluation of its dielectric properties. AIP Advances, 4: 27121

Aguilar-Frutis M., Garcia M., Falcony C., Plesch G., Jimenez-Sandoval S. (2001). A study of the dielectric characteristics of aluminum oxide thin films deposited by spray pyrolysis from Al(acac). Thin Solid Films, 389: 200-206.

Aqeel T., Greer H. F., Bumajdad A. (2018). Novel synthesis of crystalline mesoporous tin dioxide doped with nanogold. Kuwait J. Sci. 45(2): 53-63.

Armstrong A. R., Bruce P. G. (1996). Synthesis of layered $\mathrm{LiMnO}_{2}$ as an electrode for rechargeable lithium batteries. Nature, 381: 499-500.

Bhagwanti S. Bishnoi, Mehta P.K., Panchal C.J., Desai M. S., Kher V. H., Velykodnyi D. V., Protsenko I. Yu. (2014). Dielectric Relaxation in $\mathrm{Sr}\left(\mathrm{Co} 1 / 3 \mathrm{Nb}_{2} / 3\right) \mathrm{O}_{3}$ Compound - A Candidate For Microwave Applications. Proceeding of the international conference, Nanomaterials: Applications and Properties, 3(2): 02NNSA08(7pp)

Bishnupriya Behera, Renuprava Dalai, Dinesh Kumar Mishra, Sushant Kumar Badjena. (2020) Development and Characterization of $\mathrm{Al}_{2} \mathrm{O}_{3}$ and $\mathrm{SiC}$ Reinforced $\mathrm{Al}-\mathrm{Cu}$ Metal Matrix Hybrid Composites. Materials Science Forum, 978: 202-208.

Faisal M., Sher Bahadar Khan, Mohammed M. Rahman, Aslam Jamal, Abdullah M.M., (2012). Fabrication of $\mathrm{ZnO}$ nanoparticles based sensitive methanol sensor and efficient photocatalyst. Appl. Surf. Sci., 258: 7515-7522.

Faisal M., Sher Bahadur Khan, Mohammed M. Rahman, Aslam Jamal, Abdullah M. Asiri, Abdullah M. M. (2011). Smart chemical sensor and active photo-catalyst for environmental pollutants. Chem. Eng. J. 173: 178-184.

Guo P., Song H., Chen X. (2009). Electrochemical performance of graphene nanosheets as anode material for lithium-ion batteries. Electrochem. Commun., 11: 1320-1324. 
Hasan Özdemir, Faruk Öksüzömer M.A. (2020). Synthesis of $\mathrm{Al}_{2} \mathrm{O}_{3}, \mathrm{MgO}$ and $\mathrm{MgAl}_{2} \mathrm{O}_{4}$ by solution combustion method and investigation of performances in partial oxidation of methane. Powder Technology, 359: $107-117$.

Hu Wei, Li Cheng, Zheng Shun-Li, Xiang Teng-Fei, Liu Pan-Jin, Ding Shi-Bing. (2018). Synthesis of Nickel- $\mathrm{Al}_{2} \mathrm{O}_{3}$ Nanopowders and the Research of their Low Dielectric Constant Properties. Materials Science Forum, 916: 101-106.

Huiyun Ban, Yongzhe Fan, Xue Zhao, An Du, Ruina Ma, Kaixuan Chen, Xiaoming Cao, Xuan Li. (2020). Effects of $\mathrm{Al}_{2} \mathrm{O}_{3}$ on dielectric properties of core-shell $\mathrm{Ba}_{0.7} \mathrm{Sr}_{0.3} \mathrm{Ti}_{0.9925} \mathrm{Tm}_{0.0103} @ \mathrm{Al}_{2} \mathrm{O}_{3}$ ceramics. Materials Chemistry and Physics, 241: 122376.

Imen M'rad, Mustapha Jeljeli, Naima Rihane, Pascal Hilber, Mohsen Sakly, Salem Amara. (2018). Aluminium Oxide Nanoparticles Compromise Spatial Learning and Memory Performance in Rats. EXCLI Journal, 17: 200-210.

Jianyi Gao, Xuanyue Xiong, Yang Gao. (2017). The effect of the $\alpha / \gamma$ phase on the dielectric properties of plasma sprayed $\mathrm{Al}_{2} \mathrm{O}_{3}$ coatings. J Mater Sci: Mater Electron, 28: 12015-12020

Kandasamy S., Prema R. S. (2015). Methods of synthesis of nano particles and its applications. Journal of Chemical and Pharmaceutical Research., 7(3): 278-285.

Kerasidou A. P., Karahaliou P. K., Xanthopoulos N. I., Svarnas P., Georga S. N., Krontiras C. A. (2014). Electrical characteristics of $\mathrm{Al}_{2} \mathrm{O}_{3}$ and $\mathrm{Ta}_{2} \mathrm{O}_{5}$ nanoparticles synthesized by DC anodic ARC-discharge in water. IEEE Transactions on Dielectrics and Electrical Insulation, 21(1): 230-235.

Farah Kanwal, Aisha Batool, Muniba Aslam, Fatima Aziz, Shahzad Ahmad. (2021). Synthesis of coral-like silver chloride-polypyrrole nanocomposites derived from silver nanoparticles and the study of their structural, thermal, optical, and electrical properties. Kuwait J. Sci. 48(4): 1-11.

Khaleel R. S., Hashim M. S. (2020). Fabrication of $\mathrm{ZnO}$ sensor to measure pressure, humidity and sense vapors at room temperature using the rapid breakdown anodization method. Kuwait J. Sci., 47(1): 42-49.

Kingon I. A., Maria J-P., Streiffer S. K. (2000). Alternative dielectrics to silicon dioxide for memory and logic devices Nature., 406: 1032-1038.

Lee Li, Shuai Ren, Hongyu Dai, Yong Liu, Xin Gong, Jiaming Xiong, Yi Zhang, Baohong Tian. (2020). Effect of 100-nm $\mathrm{Al}_{2} \mathrm{O}_{3}$ Particle Inclusions on 100-kA Pulsed Arc Erosion of W-Cu Electrodes. IEEE Transactions on Plasma Science, 48(1); 228-238

Ma L. P., Wu Z. S., Li J., Wu E. D., Ren W. C., Cheng H. M. (2009). Hydrogen adsorption behavior of graphene above critical temperature. Int. J. Hydrogen Energy., 34: 2329-2332. 
Nguyen Anh Tuan, Nguyen Tuan Anh, Nguyen Yen Tuyet Nga, Nguyen Anh Tue, Giap Van Cuongi. (2016). Thickness-, Composition-, and Magnetic-Field-Dependent Complex Impedance Spectroscopy of Granular-Type-Barrier $\mathrm{Co} / \mathrm{Co}-\mathrm{Al}_{2} \mathrm{O}_{3} / \mathrm{Co} \mathrm{MTJ}$. Journal of Electronic Materials, 45(6): 3200-3207.

Nurhanna Badar, Norlida Kamarulzaman, Annie Maria Mahat, Nor Fadilah Chayed, Kelimah Elong. (2019). Studies on the Characteristics and the Effect of Thickness on the Band Gap Energies of $\mathrm{Al}_{2} \mathrm{O}_{3}$ Thin Films Prepared by PLD. Solid State Phenomena, 290: 163-167

Othman, K.I., Ali, M. E-S., El-Hout, S. (2019). Dielectric properties of sintered $\mathrm{BaTiO}_{3}$ prepared from barium acetate and titanium dioxide. Kuwait J. Sci., 46(3): 53-59.

Preeti Singh, Abdullah, M. M., Suresh Sagadevan, Chanmeet Kaur, Saiqa Ikram. (2019). Highly sensitive ethanol sensor based on $\mathrm{TiO} 2$ nanoparticles and its photocatalyst activity. Optik - International Journal for Light and Electron Optics, 182: 512-518.

Preeti Singh, Hasmuddin, Mohd., Abdullah, M. M., Shkir, Mohd., Wahab, M. A. (2013). Observation of crystallization and characterizations on thiourea cadmium iodide: A semi-organic optical material. Materials Research Bulletin, 48(10): 3926-3933.

Saif A. Naayi, Azhar I. Hassan, Evan T. Salim. (2018). FTIR and X-ray Diffraction Analysis of A12O3 Nanostructured Thin Film Prepared at Low Temperature Using Spray Pyrolysis Method. International Journal of Nanoelectronics and Materials, 11: 1-6

Sathiya Narayanan, Baskar N., Vedha Hari B. N., Rohith Sankaran, Ramya Devi D. (2019). Performance of Cutting Tool with Cross-Chevron Surface Texture Filled with Green Synthesized Aluminum Oxide Nanoparticles. Scientific Reports, 9: 17803.

Shankar Amalraj, Prawin Angel Michael. (2019). Synthesis and characterization of $\mathrm{Al}_{2} \mathrm{O}_{3}$ and $\mathrm{CuO}$ nanoparticles into nanofluids for solar panel applications. Results in Physics, 15: 102797

Somaparna Ghosh, Roshan Prabhakar,S. R. Samadder. (2019). Performance of $\gamma$-aluminium oxide nanoparticles for arsenic removal from groundwater. Clean Technologies and Environmental Policy, 21: 121-138

Stroller M. D., Park S., Zhu Y., An J., Ruoff R.S. (2008). Graphene-based ultracapacitors. Nano Lett., 8: 3498-3502.

Stolyarova V.V., Frolova A.V., Sudzhanskaya I.V. (2020). Dielectric properties of nanocomposite ceramics Al2O3 / graphene processed by spark plasma sintering. Ceramics International, 46: 6920-6925.

Tan Foo Khoon, Jumiah Hassan, Zaidan Abd. Wahab, Raba'ah Syahidah Azis. (2016). Electrical conductivity and dielectric behaviour of manganese and vanadium mixed oxide prepared by conventional solid-state method. Eng. Sci. Technol., 19: 2081. 
Vilar S. Y., Mira J., Sánchez-Andújar M., Castro-García S., Fondado A., Rivas J., SeñarísRodríguez M. A. (2010). Particle size reduction: A way to enhanced dielectric properties of magnetocapacitive La2/3Ca1/3MnO3. Applied Physics Letters., 96: 162904.

Wang D., Dang Z-M. (2018). Processing of Polymeric Dielectrics for High Energy Density Capacitors. In: Zhi-Min Dang (Ed). Dielectric Polymer Materials for High-Density Energy Storage. Pp. 429-446. William Andrew Publishing

Wang G. X., Shen X. P., Yao J., Park J. (2009). Graphene nanosheets for enhanced lithium storage in lithium-ion batteries. Carbon, 47: 2049-2053.

Wang X., Zhi L., Müllen K. (2008). Transparent, Conductive Graphene Electrodes for DyeSensitized Solar Cells. Nano Lett., 8: 323-327.

Woo-Sik Jung. (2010). Comparison of the carbothermal reduction and nitridation reactivity among $\gamma-, \delta$-, and $\alpha-\mathrm{Al}_{2} \mathrm{O}_{3}$. Journal of ceramic society of japan, 118(2): 132-136

Xiaohong Xu, Shixiang Zhou, Jianfeng Wu, Qiankun Zhang, Yaxiang Zhang, Guangyi Zhu. (2020). Preparation of highly dispersive solid microspherical $\alpha-\mathrm{Al}_{2} \mathrm{O}_{3}$ powder with a hydrophobic surface for stereolithography-based 3D printing technology. Ceramics International, 46: 18951906.

Submitted: $\quad 08 / 03 / 2021$

Revised: 08/04/2021

Accepted: $\quad 10 / 04 / 2021$

DOI: $\quad 10.48129 / \mathrm{kjs} .12885$ 